\title{
Pontocerebellar hypoplasia type 5
}

INSERM

\section{Source}

INSERM. (1999). Orphanet: an online rare disease and orphan drug data base.

Pontocerebellar hypoplasia type 5. ORPHA:166068

Pontocerebellar hypoplasia type $5(\mathrm{PCH} 5)$ is a very rare severe form of $\mathrm{PCH}$ (see this terme) with prenatal onset and characterized by fetal onset of clonus or seizures-like activity persisting in infancy and microencephaly leading to early postnatal death. There is significant overlap both in phenotype and in genotype between pontocerebellar hypoplasia types 4 and 5 . 